\title{
Lipoprotein (a) level and hsCRP as risk markers in Myocardial Ischemia
}

\author{
Leela $\mathbf{P}^{1, *}$, C.R. Mallikarjuna ${ }^{2}$, Shreedhar .A. $\mathbf{M}^{3}$ \\ ${ }^{\mathbf{1}}$ Assistant Professor, Dept. of Biochemistry, Subbaiah Institute of Medical Sciences, Shimoga, Karnataka, ${ }^{2}$ Professor \& HOD, \\ Dept. of Biochemistry, SSIMS \& RC, Davangere, Karnataka, ${ }^{3}$ Anaesthesiologist, Dept. of Anaesthesiology, General Hospital, \\ Channagiri, Davangere, Karnataka, India
}

*Corresponding Author: Leela $\mathbf{P}$

Email: leelapleela@gmail.com

Received: $26^{\text {th }}$ May, 2018

Accepted: $18^{\text {th }}$ August, 2018

\begin{abstract}
Cardiovascular diseases are the major cause of death globally. Hyperlipidemias and hyperlipoproteinemias are the most important risk factors for atherosclerosis. Inflammation plays a major role in atherothrombosis, and measurement of inflammatory biomarkers like High Sensitive C- reactive protein (hsCRP) can provide detection of high risk for Ischemic Heart Disease (IHD). Lipoprotein (a) [Lp (a)] is a low density lipoprotein like particle synthesized by the liver. There is a strong association between circulating $\mathrm{Lp}(\mathrm{a})$ levels and IHD.

Objectives: To estimate the serum levels of lipoprotein (a) and lipid profile in ischemic heart disease patients and healthy subjects and to show that serum hsCRP as a better predictor of ischemic heart disease than low density lipoprotein cholesterol.

Materials and Methods: A total number of 100 subjects were studied comprising of 50 controls and 50 IHD subjects. Total cholesterol (TC), triglycerides (TGL) and HDL-C, were estimated by enzymatic methods, LDL-C and VLDL-C were estimated by calculation, $\mathrm{Lp}$ (a) was estimated by immunoturbidimetric methods and hsCRP was estimated by chemiluminiscence method. Appropriate statistical analysis was done.

Results: TC, TGL, LDL-C, VLDL-C, Lp(a) and hsCRP were increased whereas HDL-C was decreased in IHD subjects when compared to controls. Diagnostic validity test revealed that hsCRP to be a better discriminator of IHD than LDL-C.

Conclusion: The results of the current study support the concept that the levels of Lp(a), and hsCRP are strongly related to ischemic heart disease in addition to the levels of serum lipids.
\end{abstract}

Keywords: Ischemic heart disease, High sensitive C-reactive protein, Lipoprotein (a), Hyperlipoproteinemia.

\section{Introduction}

Myocardial Infarction (MI) is one of the major cause of morbidity and mortality in the world and the cause for ischemic heart disease (IHD) is atherosclerosis. ${ }^{1}$ IHD is a condition in which a portion of the myocardium is lack with supply of blood and oxygen; it typically occurs when there is an imbalance between myocardial oxygen supply and demand. The common cause of myocardial ischemia is an epicardial coronary artery (or arteries) with atherosclerotic disease which leads to a regional reduction in myocardial blood flow and inadequate perfusion of the myocardium. Dyslipidemia is the most important risk factor for atherosclerosis. IHD causes more deaths and disability and incurs greater economic costs than any other illness in the developed world. ${ }^{2}$

C-reactive protein (CRP) is an acute phase reactant protein produced in response to inflammation by liver and found in the blood. ${ }^{1}$ Chronic inflammation is an important component in the development and progression of atherosclerosis and various epidemiological studies have explained that increased serum CRP concentrations are positively associated with a risk of future coronary artery disease, cerebrovascular disease or peripheral arterial disease. ${ }^{3}$ High sensitivity C-Reactive Protein (hsCRP) is useful in the measurement of very low levels of CRP (< $0.03 \mathrm{mg} / \mathrm{dL}$ ) in blood, hence inflammatory biomarker such as hsCRP can provide detection of high risk for IHD. ${ }^{1}$

Lipoprotein (a) [Lp (a)] is a low density lipoprotein like particle synthesized by the liver that contains an apo B molecule covalently bound to a very large glycoprotein known as apolipoprotein a. ${ }^{4}$ However, unlike LDL-C, Lp(a) contains apo (a) which is a carbohydrate-rich protein covalently attached to the apo B-100 through a disulfide linkage. The available evidence suggest that $\mathrm{Lp}$ (a) contains one molecule of apo (a) and one molecule of apo B-100. Apo (a) is an unique protein of $\mathrm{Lp}(\mathrm{a})$ and exhibits a significant sequence homology with plasminogen and a high degree of variation in polypeptide chain length. ${ }^{3}$ Lp (a) is a part of low density lipoprotein cholesterol, having a pro-atherogenic and hypofibrinolytic effect. ${ }^{5}$

Therefore the present study was undertaken to measure the serum concentrations of lipoprotein (a) and lipid profile in ischemic heart disease patients and healthy controls, to evaluate whether the serum hsCRP is a better marker of IHD than low density lipoprotein cholesterol (LDL-C).

\section{Materials and Methods}

A case control study was carried out in clinically proven cases of IHD and age and sex matched healthy individuals as controls. Serum concentrations of lipoprotein (a), hsCRP and lipid profile was carried out 
in both cases and control group after obtaining Institutional Ethical Clearance. A total number of 50 IHD patients and an equal number of controls were selected based on inclusion and exclusion criteria for the present study. Written informed consent was taken from each subject.

Inclusion Criteria: IHD cases diagnosed clinically either by electrocardiogram (ECG) and/or troponin-I in the age group of 30-70 years and an equal number of healthy controls with age and sex matched were included.

Exclusion Criteria: IHD patients with sepsis, diabetes mellitus, malignancy, anemia, hepatic and renal disease, hypolipidemic drugs were excluded from the study.

Sample Collection: About $6 \mathrm{ml}$ of venous blood was drawn in a sterile vacutainer after a period of overnight fasting of 10-12 hours under aseptic precautions from selected subjects. Serum was immediately separated by centrifugation. The TC (CHOD-PAP method), ${ }^{6}$ TGL (GPO-PAP method), ${ }^{7}$ HDL-C (Phosphotungstic acid method, End point method $)^{8}$ were analysed by using semi auto analyzer, $\operatorname{Lp}(\mathrm{a})$ was analyzed by immunoturbidimetric method using Agappe kit in semi auto analyzer ${ }^{9}$ and hsCRP by acculite which employs immunoenzymometric chemiluminescence technique. LDL-C level was calculated by using Friedewald equation based on the levels of TC, TGL and HDL-C. VLDL-C is calculated by TGL/ $5 .^{3}$

\section{Statistical Analysis}

Data obtained are presented as mean \pm SD. For comparing the means of two groups student's unpaired ' $t$ '-test was used. Diagnostic validity tests were performed for selected variables. Relationship between measurements was assessed by Karl Pearson's coefficient of correlation. A p-value of 0.05 or less was considered as statistically significant.

\section{Results and Discussion}

IHD is one of the important cause for morbidity and mortality in most countries of the world. The debate on the value of lipids as a predictive risk factor for atherogenesis has centered for many years on TC, TGL and LDL. Recently the interest has been focused on role of apolipoprotein and inflammatory marker in atherogenesis.

Table 1: Age-wise distribution of controls and cases.

\begin{tabular}{|l|c|c|c|c|}
\hline & \multicolumn{2}{|c|}{ Controls } & \multicolumn{2}{c|}{ Cases } \\
\hline Age (Years) & Female & Male & Female & Male \\
\hline $30-39$ & 01 & 02 & 01 & 02 \\
\hline $40-49$ & 02 & 03 & 01 & 05 \\
\hline $50-59$ & 09 & 11 & 08 & 10 \\
\hline $60-70$ & 09 & 13 & 10 & 13 \\
\hline Total & 21 & 29 & 20 & 30 \\
\hline Mean \pm SD & \multicolumn{2}{|c|}{$52.7 \pm 11.0$} & \multicolumn{2}{c|}{$56.3 \pm 8.8$} \\
\hline
\end{tabular}

Table 1 shows that the incidence of IHD in men is more compared to women. The incidence of IHD increased after 50 years in women probably due to the decreased protective mechanism of oestrogen in the postmenopausal period.

Table 2: Comparison of $\operatorname{Lp}(a)$, hsCRP, lipid profile and ratios in controls and in patients with ischemic heart disease

\begin{tabular}{|l|c|c|c|}
\hline \multicolumn{1}{|c|}{ Parameters } & Controls & Cases & \\
\hline Lp $(\mathrm{a})(\mathrm{mg} / \mathrm{dL})$ & Mean \pm SD & Mean \pm SD & p*- Value, Sig \\
\hline hsCRP $(\mu \mathrm{g} / \mathrm{mL})$ & $10.12 \pm 6.00$ & $16.9 \pm 7.39$ & $\mathrm{p}<0.001$ \\
\hline TC $(\mathrm{mg} / \mathrm{dL})$ & $1.396 \pm 0.567$ & $2.733 \pm 1.546$ & $\mathrm{p}<0.001$ \\
\hline TGL $(\mathrm{mg} / \mathrm{dL})$ & $147.38 \pm 32.47$ & $202.75 \pm 33.13$ & $\mathrm{p}<0.001$ \\
\hline HDL-C $(\mathrm{mg} / \mathrm{dL})$ & $115.98 \pm 40.35$ & $168.73 \pm 71.37$ & $\mathrm{p}<0.001$ \\
\hline LDL-C $(\mathrm{mg} / \mathrm{dL})$ & $44.53 \pm 8.24$ & $33.83 \pm 5.84$ & $\mathrm{p}<0.001$ \\
\hline VLDL-C $(\mathrm{mg} / \mathrm{dL})$ & $107.24 \pm 25.60$ & $134.73 \pm 35.88$ & $\mathrm{p}<0.001$ \\
\hline TC $/ \mathrm{HDL}-\mathrm{C}$ & $23.2 \pm 8.07$ & $34.2 \pm 13.55$ & $\mathrm{p}<0.001$ \\
\hline LDL-C $/ \mathrm{HDL}-\mathrm{C}$ & $3.41 \pm 0.90$ & $6.20 \pm 1.56$ & $\mathrm{p}<0.001$ \\
\hline
\end{tabular}

Student's unpaired t- test, $\mathrm{p}<0.001 \mathrm{HS}$ (Highly significant)

The mean serum concentrations of TC, TGL, LDL$\mathrm{C}$ and VLDL-C were higher in IHD subjects when compared to controls and thus had a positive correlation. The mean serum concentration of HDL cholesterol was lower in IHD subjects when compared to controls suggesting a negative association toIHD. These results were in accordance with the studies of 
Lhamo Y. Sherpa, et $\mathrm{al}^{10}$ and M. Mohsen Ibrahim, et al. ${ }^{11}$ The predictive of increased IHD risk is associated with smaller, denser LDL particles, this may be due to close relationship between phenotype and altered plasma lipid levels. It has been noticed that the hepatic LDL apo B/E receptor have lower affinity for dense LDL-C. In normolipidemic individuals LDL-C subfractions of intermediate density, generally found at higher concentrations bind to the LDL receptor with higher affinity and are degraded with increased rates than the denser LDL subfraction. Denser LDL particles are more prone for oxidation. The capacity of binding of dense LDL particles to the intimal proteoglycans also depends on its atherogenicity. ${ }^{12}$

The ratios of TC / HDL-C, LDL-C / HDL-C were increased in IHD subjects when compared to controls and was statistically significant with $\mathrm{p}$ value $<0.001$. It was found to be a better indicator and this result was in agreement with the previous report. ${ }^{13}$ The ratio of LDL$\mathrm{C}$ to HDL-C is a better predictor of IHD than either measurement alone. ${ }^{14,15}$

The serum concentration of hsCRP was increased in patients with IHD when compared to controls. There is a positive association between IHD and hsCRP levels and the results were in agreement with those of Mukta N Chowta, et al, ${ }^{16}$ Marc S. Sabatine, et al, ${ }^{17}$ Shital S Ghodke, et al ${ }^{18}$ and Michael B Clearfield. ${ }^{19}$

In response to pro-inflammatory cytokines, and the cytokine interleukin-6 the inflammatory biomarker such as hsCRP is produced and reflects low-grade systemic inflammation. Cytokines interleukin-6 releases due to inflammation and thought to be largely responsible for triggering the production of CRP, which is thus generally viewed as a marker of inflammation, with very high values associated with acute inflammation. Chronic, low-level inflammation can result in nearnormal values. In apparently healthy men and women elevated levels of hsCRP have been shown to be predictive of increased risk of coronary artery disease. ${ }^{16}$

Inflammation plays a critical role in the development, progression and rupture of atherosclerosis. This ruptured atherosclerotic plaque bind to leukocytes and endothelial cells and causes both upregulation of adhesion molecules and decreased production of nitric oxide and to induce atherosclerosis, thrombosis and increase infarct size. ${ }^{20}$

The $L p(a)$ concentration was increased in patients with IHD when compared to age matched healthy normal individuals. This study showed a positive association between IHD and Lp(a) level and the results were in agreement with those of John Danesh et al, ${ }^{21}$ Mika Kivimaki et al, ${ }^{22}$ and Pai R Kamstrup et al. ${ }^{23}$

The $\mathrm{Lp}(\mathrm{a})$ levels were associated with the presence of coronary artery stenosis and also with the severity of the coronary atherosclerosis. In young and middle aged men and women an increased $\mathrm{Lp}$ (a) level is thought to be an important cardiovascular risk factor. ${ }^{5}$ The risk associated with apolipoprotein B and TC is enhanced by elevated $\mathrm{Lp}(\mathrm{a})$ levels. The beneficial effects associated with elevated HDL cholesterol levels were lost in the presence of elevated Lp(a) levels even though HDL-C particles may not be directly related to it. $^{24}$

Table 3: Diognostic validity of hsCRP and LDL-C cholesterol discrimination of ischemic heart disease subjects

\begin{tabular}{|l|c|c|}
\hline Diagnostic validity test result & $\begin{array}{c}\text { hsCRP cut off value } \\
\mathbf{1} \mathbf{1 . 6 5 5} \mathbf{\mu g} / \mathbf{m L}\end{array}$ & $\begin{array}{c}\text { LDL-C cut off value } \\
\mathbf{1 1 6 . 6} \mathbf{~ m g} / \mathbf{d L}\end{array}$ \\
\hline Sensitivity & $75 \%$ & $67.5 \%$ \\
\hline Specificity & $72.5 \%$ & $65 \%$ \\
\hline Positive predictive value (PPV) & $73 \%$ & $65.8 \%$ \\
\hline Negative predictive value (NPV) & $74 \%$ & $66.6 \%$ \\
\hline Diagnostic efficiency & $73.7 \%$ & $66.3 \%$ \\
\hline
\end{tabular}

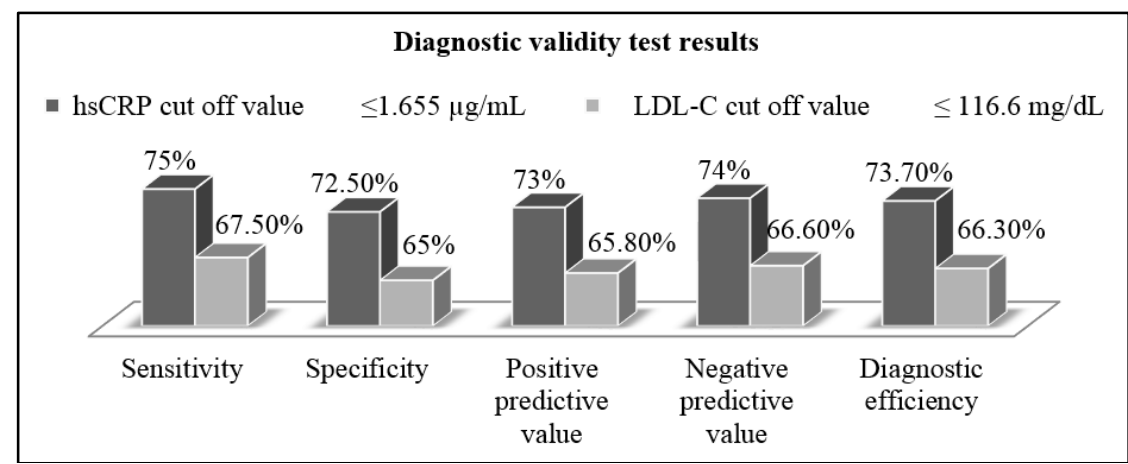

Fig. 1: Diognostic v alidity of hsCRP and LDL-C cholesterol discrimination of ischemic heart disease subjects 
Table 3 and Fig. 1 shows the diagnostic validity results with higher sensitivity, specificity, PPV, NPV and greater diagnostic efficiency for hsCRP when compared to LDL -C suggesting superiority of hsCRP over LDL in predicting IHD and in discriminating IHD from normal healthy individuals. The results were in accordance with those of Subinay Dutta et al. Recent studies have shown that the size of LDL particle is more important as compared to LDL-C concentration in atherosclerosis. ${ }^{1}$

Table 4: Karl pearson's coefficient ( $r$ ) of correlation

\begin{tabular}{|l|c|c|c|c|c|c|}
\hline & \multicolumn{3}{|c|}{ hsCRP } & \multicolumn{3}{c|}{ Lipoprotein (a) } \\
\hline Correlation between & $\mathbf{r}$ & $\mathbf{p}^{*}$ value & Sig & $\mathbf{r}$ & $\mathbf{p}^{*}$ value & Sig \\
\hline TC & -0.21 & 0.17 & NS & -0.18 & 0.26 & NS \\
\hline TGL & 0.05 & 0.73 & NS & 0.18 & 0.25 & NS \\
\hline HDL-C & 0.26 & 0.1 & NS & 0.18 & 0.24 & NS \\
\hline LDL-C & 0.29 & 0.06 & NS & 0.28 & 0.08 & NS \\
\hline VLDL-C & 0.12 & 0.43 & NS & 0.22 & 0.17 & NS \\
\hline
\end{tabular}

Table 4 shows that there is a positive correlation between LDL-C, and Lp(a) in karl pearson's coefficient but is not statistically significant.

Lipoprotein (a) may contribute to the development of MI by different mechanisms: LDL-C particle present in lipoprotein (a) may promote atherosclerosis and a plasminogen-like apolipoprotein (a) particle that may interfere with fibrinolysis and increase the risk of thrombosis. Lipoprotein (a) can enter into human atherosclerotic plaques, smooth muscle cell proliferation and plaque inflammation and instability. Lipoprotein (a) has also been shown to bind proinflammatory oxidized phospholipids recently associated with coronary artery disease. Lipoprotein (a) enters into and leaves the arterial wall by mechanisms similar to LDL and appears to accumulate more at sites of arterial injury than LDL. Mechanisms by which Lp (a) may contribute to thrombus formation include inactivation of tissue factor pathway inhibitor, thus promoting coagulation and attenuation of fibrinolysis through inhibition of plasminogen activation. ${ }^{25,23}$

\section{Strength and Further Scope}

The concentrations of $\mathrm{Lp}(\mathrm{a})$, hsCRP and lipid profile were significantly increased in patients with IHD as compared to control group except, HDL which was statistically decreased in IHD subjects compared to controls. This study also proved that hsCRP is the better biomarker with high sensitivity and specificity of IHD than LDL cholesterol.

The diagnosis of IHD can be improved by measuring newer markers of IHD like oxidized LDL, Homocysteine levels and Interleukin-6.

\section{Conclusion}

The recommended lipid variables in international guidelines for diagnosis and treatment of IHD disease are TC, TGL, HDL-C and LDL-C. However, recent information shows the importance of $L p(a)$ and hsCRP as risk predictors of suspected IHD. Our findings support the consideration of the estimation of serum $\mathrm{Lp}$ (a) as a screening tool for the risk of IHD.
Inflammation plays a major role in atherothrombosis and hence the measurement of hsCRP may provide a promising novel biochemical marker for risk assessment in IHD.

\section{Acknowledgement}

The authors are thankful to the subjects without whose cooperation the work would not have been completed.

\section{References}

1. Dutta S, Iqbal Z, Prasad KR. Comparison between serum hsCRP and LDL cholesterol for search of a better predictor for Ischemic heart disease. Ind J Clin Biochem. 2011;26(2):210-13.

2. Longo DL, Fauci AS, Kasper DL, Hauser SL, Jameson JL, Loscalzo editors. Harrison's Principle of Internal Medicine, $18^{\text {th }}$ ed. USA: McGraw Hill Co; 2012.

3. Miremadi S, Sniderman A, Frhlich J. Can measurement of serum apolipoprotein B replace the lipid profile monitoring of patients with lipoprotein disorders?. Cinical Chemistry. 2002;48(3):484-88.

4. Bennet A, Angelantonio ED, Ergou S, Eiriksdottir G, Sigurdsson G, Woodward M et al. Lipoprotein (a) levels and risk of future coronary heart disease. Arch Intern Med. 2008;168:598-608.

5. Rifai N, Warnick GR. Lipids, lipoproteins, apolipoproteins and other cardiovascular risk factors. In: Burtis CA, Ashwood ER and Bruns DA, editors. Tietz Text Book of Clinical Chemistry and Molecular Diagnostics, 4th ed. New Delhi: Elsevier Co;2006:90364.

6. Allain CC, Poon LS, Chan CSG, Richmond W, Fu PC. Enzymatic determination of total serum cholesterol. Clin Chem. 1974;20(4):470-75.

7. McGowen MW, Artiss JD, Strandbergh DR, Zak B. A Peroxidase Coupled Method for the Colorimetric Determination of Serum Triglycerides. Clin Chem. 1983;29(3):538-42.

8. Burstein M, Scholnick HR, Morfin R. Rapid method for the isolation of lipoproteins from human serum by precipitation with polyanions. Journal of Lipid Research. 1970;11:583-95.

9. Gaubatz JW, Heideman C, Gotto AM, Jr, Morrisett JD, Dahlen GH. Human plasma lipoprotein (a) structural properties. J Biol Chem. 1983;258:4582-89. 
10. Sherpa LY, Deji, Stigum H, Chongsuvivatwong V, Luobu O, Thelle DS, et al. Lipid profile and its association with risk factors for coronary heart disease in the highlanders of Lhasa, Tibet. High Altitude Medicine \& Biology. 2011;10(1):57-63.

11. Ibrahim MM, Ibrahim A, Shaheen K, Nour MA. Lipid profile in Egyptian patients with coronary artery disease. The Egyptian Heart Journal. 2013;65:79-85.

12. Lamarche B, Chernof AT, Moorjani S, Cantin B, Dagenais GR, Lupein PJ, et al. Small, dense low-density lipoprotein particles as a predictor of the risk of ischemic heart disease in men. Circulation. 1997;95:69-75.

13. Lemieux I, Lamarche B, Couillard C, Pascot A, Cantin B, Bergeron J, et al. Total cholesterol/ HDL cholesterol ratio vs LDL cholesterol/ HDL cholesterol ratio as indices of ischemic heart disease risk in men. Arch Intern Med. 2001;161:2685-92.

14. Miller NE, Hammett F, Saltissi S, Rao S, Zeller HV, Coltart J et al. Relation of angiographically defined coronary artery disease to plasma lipoprotein subfractions and apolipoproteins. British Medical Journal. 1981;30;282:1741-44.

15. Stampfer MJ, Sacks FM, Salvini S, Willett WC, Hennekens CH. A prospective study of cholesterol, apolipoproteins and the risk of myocardial infarction. The N Engl J Med. 1991;325:373-81.

16. Chowta MN, Adhikari PM, Sinha R, Acharya SD, Gopalakrishna HN, Ramapuram JT. Highly sensitive C reactive protein in patients with metabolic syndrome and cardiovascular disease. 2012;5(2):98-102.

17. Sabatine MS, Morrow DA, Jablonski KA, Rice MM, Warnica JW, Domanski MJ, et al. Prognostic significance of the centers for disease control/ American heart association high sensitivity $\mathrm{C}$-reactive protein cut points for cardiovascular and other outcomes in patients with stable coronary artery disease. Journal of the American Heart Association circulation. 2007;115:1528-36.
18. Ghodke SS, Padalkar RK, Bhagat SS, Ghone RA, Patil SM. hs- CRP: A "golden marker" of inflammation and coronary artery disease. IJHSR. 2012;2(6):42-6.

19. Clearfield MB. C-reactive protein: a new risk assessment tool for cardiovascular disease. JAOA. 2005;105(9):40916.

20. Miremadi S, Sniderman A, Frhlich J. Can measurement of serum apolipoprotein B replace the lipid profile monitoring of patients with lipoprotein disorders? Cinical Chemistry. 2002;48(3):484-88.

21. Danesh J, Collins R, Peto R. Lipoprotein (a) and coronary heart disease: Meta analysis of prospective studies. Circulation. 2000;102:1082-85.

22. Kivimaki M, Magnussen CG, Juonala M, Kahonen M, Kettunen J, Loo BM, et al. Conventional and mendelian randomization analyses suggest no association between lipoprotein (a) and early atherosclerosis: the young Finns study. International Journal of Epidemiology. 2011;40:470-78.

23. Kamstrup PR, Benn M, Hansen AT, Nordestgaard BG. Extreme lipoprotein (a) levels and risk of myocardial infarction in the general population. Circulation. 2008; 117:176-84.

24. Cantin B, Gagnon F, Moorjani S, Despres JP, Lamarche $\mathrm{B}$, Lupien PJ, et al. Is lipoprotein (a) an indendent risk factor for ischemic heart disease in men? The Quebec cardiovascular study. JACC. 1998;31:519-25.

25. Ariyo AA, Thach C, Tracy R. Lp (a) lipoprotein, vascular disease and mortality in the elderly. $N$ Engl J Med. 2003;349 (22):2108-15.

How to cite this article: Leela $\mathrm{P}$, Mallikarjuna C.R, Shreedhar A. M. Lipoprotein (a) level and hsCRP as risk markers in myocardial ischemia. Int J Clin Biochem Res. 2018;5(4):646-650. 